\title{
Socioeconomic Burden of Malaria on Productivity of Rice Farmers in Rural Southwest, Nigeria
}

\author{
Isaac B. Oluwatayo, PhD \\ Department of Agricultural Economics and Animal Production, \\ School of Agricultural and Environmental Sciences, \\ University of Limpopo, Sovenga 0727, South Africa \\ Email: isaac.oluwatayo@ul.ac.za
}

Doi:10.5901/mjss.2014.v5n15p175

\begin{abstract}
Malaria is one of the commonest tropical diseases plaguing the African continent and the rural areas of the continent in particular. This study was carried out to examine the effect of malaria on the productivity of rice farmers in Southwest Nigeria. The data for this study were obtained from one hundred and fifty (150) rice farmers in Ogun State and Ekiti State by purposive and simple random sampling techniques. The data were analyzed using descriptive statistics, Tobit regression and stochastic frontier regression model. The result of the analysis showed that more males (84\%) were involved in rice production and about $72 \%$ of the farmers were susceptible to malaria. Average days of incapacitation due to malaria in the study area was found to be 10 days and the result of the Tobit regression also revealed that age, gender, income and years of formal education were significant. However, the mean technical efficiency of the farmers was also found to be 75 percent, indicating that about $25 \%$ have the potential to improve their output further if there is improvement in the health status and production environment of the farmers.
\end{abstract}

Keywords: Health status, Malaria burden, Productivity, Rice farmers, Southwest Nigeria

\section{Introduction}

Malaria and agriculture are intimately related. This is because agricultural environments provide suitable conditions for breeding of disease vector which causes malaria in human beings. There are multiple channels by which malaria impedes development, including effects on fertility, population growth, saving and investment, worker productivity, absenteeism, premature mortality and medical costs (Sachs and Malaney, 2010). Malaria's effect on smallholders can be devastating. Taking ill at planting season, a farmer may not be able to cultivate as much land and engage in intensive farming practices. He may then plant less labor-intensive crops and change cropping patterns, perhaps raising crops with a lower return, and fewer of them.

United Nations report observed that "a brief period of illness that delays planting or coincides with the harvest may result in catastrophic economic effects." Malaria transmission generally coincides with the planting and harvesting seasons, making the illness's impact particularly damaging. Farm households may also withdraw savings, sell productive assets, or borrow money to pay for treatments. Fewer improvements may be made to farms, further decreasing their productivity even when illness is not an issue (Kwadwo Asenso-Okyere et al, 2011). The fight against malaria is far from over: the population at risk continues to be significant (nearly 300 million clinical cases in the world, WHO, 1999), but it is still not easy to diagnose the disease (Rougemont et al, 1991).

Among the major diseases that are common in Africa, Malaria is one of the greatest threats facing development in Africa today. It attacks an individual on average of four times in a year with an average of 10 to 14 days of incapacitation (Alaba and Alaba, 2002). Recent estimate indicates that between 700,000 and 2.7 million people die annually from malaria. Over 75 percent of these mortality figures are African children (Multilateral Initiative on Malaria (MIM), 2001). In addition to its health impact, malaria is an obstacle to social and economic development. According to recent estimates the direct and indirect costs of malaria exceeded US \$2 billion in 1997 and this figure is likely to increase every year. (Alaba and Alaba, 2002). Furthermore, on a global perspective between 400 and 900 millions of children under the age of 5 experience acute malaria annually in this malaria endemic region and that this number may double by year 2020 if effective control measures are not implemented (MIM, 2001).

Eyo et al. (2006) reported that farmers' health status has a significant effect on their capacity to increase output, otherwise ill health could impact negatively on the number of hours spent on farm and amount of income earned. Health 
risk and particularly malaria has some debilitating effects on the output and income through cost of health care, labour man days lost to malaria medication and physical weakness. Malaria leads to loss of agricultural labour due to illness and death, wastage of family members' time and energy in caring for malaria patients and grieving for people killed by malaria. Malaria also results into loss of agricultural knowledge and skills especially if it kills an experienced farmer.

The Nigerian rice sector is special within the West Africa context. First, rice is primarily a cash crop in Nigeria (produced primarily for the market). Therefore, in rice producing areas, the enterprise provides employment for more than $80 \%$ of the inhabitants in various activities along the production/distribution chain from cultivation to consumption. Irrigation has conventionally been associated with an increase in malaria burden (Mutero, 2005). Rice production in Nigeria is insufficient to match the consumption increase - with rice imports making up the shortfall. Because rice is now a structural component of the Nigerian diet and rice imports make an important share of Nigerian agricultural imports, there is considerable political interest in increasing the consumption of local rice. Nigeria is one of the biggest producers of rice in Africa and the consumers require that the domestically produced rice should satisfy minimum level of quality, health and food security standards (Baksh, 2003). Rice is cultivated in virtually all the agro-ecological zones in Nigeria (Akande, 2001). Cultivation of rice in appreciable scale and dimension commenced in Nigeria during the Second World War due to a halt in the importation from the East (Ojo, 1991). Health risk and particularly malaria has some debilitating effects on the output and income through cost of health care, labour man days lost to malaria medication and physical weakness. Malaria disease accounts for as much as $40 \%$ of public health expenditure. Attempts to ascertain the effect of malaria on rice producing households' economy have all focused on the direct and indirect expenditure of household resources on malaria with limited focus on quantifying its effect on rice production. Hence, the study attempts to identify the effects of some socio-economic variables on the incidence of malaria among rice farmers in the study area, assess the mean number of days of incapacitation due to malaria attack in the region and examine the consequences of malaria disease on the productivity of rice farmers in Ogun and Ekiti States.

\section{Methodology}

\subsection{The Study Area}

The Study area chosen for this study comprised of both Ogun and Ekiti States being the hub of various varieties of rice widely grown in southwest Nigeria. Farming predominates in the study area and the common crops include cocoa, rice, yam, maize, etc. Ekiti is an upland rice ecology and Ifelodun//repodun LGA Ekiti was chosen being an important upland rice producing area in Ekiti State. Here, rice cultivation is also rainfed but the upland type dominates. While, Obafemi-Oba local government of Ogun State is the highest producer of rice within the southwest geopolitical zone.

\subsection{Sampling Techniques}

Purposive sampling and simple random sampling techniques were employed for the research survey through well structured questionnaires. Purposive sampling was used for the selection of Ekiti and Ogun States as representative states within the southwest region of Nigeria and in selecting Irepodun/ifelodun and Obafemi-Oba Local Government in each of the states respectively. Ogun and Ekiti States were selected because of their relative importance in rice production landscape in Nigeria. Purposive sampling was also used for selecting 4 villages from each of the selected local governments. The communities selected in Obafemi-oba local government are; Ofada, Egbeda, Oba and Owode. In Irepodun/ifelodun local government, the communities include; Igbemo Ekiti, Ajebandele, Ogbese and Awo Ekiti. From Irepodun/ifelodun Local Government, 70 respondents were selected using simple random sampling technique while 80 respondents were selected from Obafemi-Owode local government to make up with 150 respondents. The variation in sample size is due to the fact that the population size of Obafemi-Owode is higher than that of Irepodun/lfelodun. The sample size was chosen in view of the expected level of precision required in estimate, the level of variability of variables, the nature of data requirement aimed at capturing the productivity and efficiency of the farmers. Data was collected on the socio-economic characteristics and also on malaria incidence as it affects the rice farmers' health and their agricultural labour productivity.

\subsection{Analytical Techniques}

Data collected were analyzed using descriptive and inferential statistics. Descriptive statistics such as frequency tables and percentages were employed in the analysis of the socioeconomic characteristics of the respondents, distribution of 
farmers according to the number of days of incapacitation, distribution of farmers according to the source employed for treating the disease as well as distribution of farmers according to the preventive methods adopted.

\subsubsection{Socioeconomic Status and Malaria Incidence in Southwest Nigeria}

The Tobit regression analysis was used to analyse the effects of some socioeconomic variables on malaria incidence among rice farmers in the study area. The standard Tobit model can be written as (Tobin, 1958):

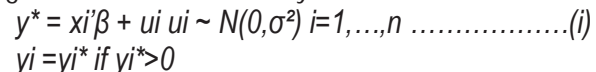

$y i=0$ otherwise

yi = Incidence of malaria (measured as number symptoms reported by each respondents over the total number of symptoms available)

The explanatory variables are:

$x_{1}=$ Age of farmers (years)

$x_{2}=$ Marital Status of farmers (married $=1$, otherwise $=0$ )

$x_{3}=$ Household size

$x_{4}=$ Years of formal education

$x_{5}=$ Gender of farmers $($ male $=1$, female $=0$ )

$x_{6}=$ Years of Experience in farming (years)

$x_{7}=$ Income of farmers (in naira)

$x_{8}=$ Farm size (hectares)

$x_{9}=$ Working hours per day

Where:

$x_{i}$ are a vector of explanatory variables corresponding to the ith respondent,

$y_{i}$, are observed proportion of the ith respondents with malaria and

$y_{i}{ }^{*}$ is an unobserved continuous latent variable assumed to determine the value of $y i$ while;

$u_{\mathrm{i}}$ is the disturbance term.

\subsubsection{Malaria and Rice farmers' Technical Efficiency}

Stochastic Frontier regression was used to assess the effects of malaria on rice farmers' technical efficiency following Okoruwa and Agulana (2004); Adeoti (2004); Kumbhakar, Ghosh and McGuckin (1991); and Battese and Coelli (1995). This model allows for the presence of technical inefficiency, while acknowledging that random shocks outside producers' control can affect the output. The stochastic production frontier model for a cross-sectional data is modeled as follows:

$\ln \left(Y_{i}\right)=\ln X_{i} b+v_{i}-u_{i}$

Where: $\ln \left(Y_{i}\right)$ denotes the natural logarithm of the output of the ith sample farm $(I=1, \ldots \ldots, N)$;

$X_{i}$ is a $(1-k)$ vector of the associated inputs;

$b$ is a $(k-1)$ vector of unknown parameters to be estimated.

It is assumed that the stochastic term vi is distributed as $\mathrm{N}(0, \sigma 2 \mathrm{v})$ and that the error term $\varepsilon i=v i$-ui is asymmetric, since $u i \geq 0$. Using a single-output multiple-input Cobb-Douglas stochastic production frontier, the output for the ith farm is modeled as follows and analysed using LIMDEP:

$\ln \left(Y_{i}\right)=b_{0}+b_{1} \ln \left(X_{i}\right)+b_{2} \ln \left(X_{2}\right)+b_{3} \ln \left(X_{3}\right)+b 4 \ln \left(X_{4}\right)+b_{5} \ln \left(X_{5}\right)+\ln v_{i}-u_{i}$

Where:

$\ln \left(Y_{i}\right)=$ natural log of rice farmers' output in $\mathrm{kg}$

$\ln \left(X_{i}\right)=$ natural $\log$ of total arable land cultivated in hectares.

$\ln \left(X_{2}\right)=$ natural log of total number of hours worked on the farm by the respondents hired in standard days

$\operatorname{Ln}\left(X_{3}\right)=$ natural $\log$ of quantity of seed in $\mathrm{kg}$

$\operatorname{Ln}\left(X_{4}\right)=$ natural $\log$ of quantity of agrochemicals in litres

$\ln \left(X_{5}\right)=$ natural $\log$ of quantity of fertilizer used in $\mathrm{kg}$

$V_{i}=$ random variability in production that cannot be influenced by the farmer.

$\mu_{i}=$ deviation from maximum potential output attributable to technical inefficiency.

Direct estimates of the parameters will be obtained using the Maximum likelihood method following Aigner, Lovell and Schmidt (1977):

$\operatorname{Ln} X=\Sigma i \ln L i=\Sigma i[-\ln \delta-1 / 2 \ln (2 / \pi)-(\varepsilon i / \delta) 2+\ln \theta(-\varepsilon N \delta)]$ 
Where: I = number of observations;

$\delta=(\delta 2+\delta \mathrm{u} 2) 1 / 2 ; \lambda=\delta \mathrm{u} / \delta$;

$\varepsilon i=$ vi- $\mu$ i and $\theta=$ normal distribution

Having determined the technical inefficiency, the effect of socioeconomic factors on the efficiency was examined by studying the relationship between the socioeconomic factors and the technical inefficiency determined $(\mu i)$. Average level of technical inefficiency measured by mode of truncated normal distribution has been assumed (Dawson et al, 1991, and Yao and Liu, 1998) to be a function of socio economic factor as shown in the equation below.

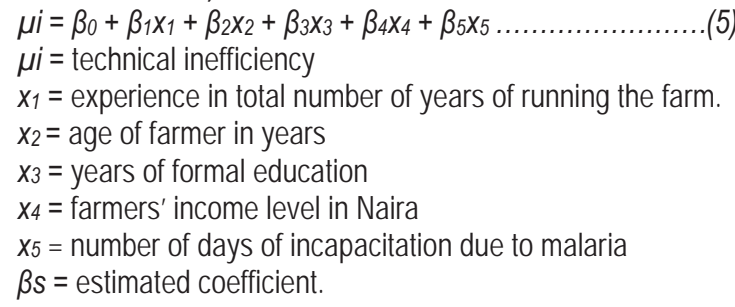

\section{Results and Discussion}

\subsection{Socioeconomic Characteristics of Respondents}

The result shown in Table 1 depicts the fact that considerable young adults are involved in rice farming in the two states. Thus, more than one-third the respondents (39.4\%) were between the age of 41 and 50 years and the mean age of the farmers was 42.19 years. A high proportion of the respondents were males (84\%), thereby re-validating the age-long dominance of men in agriculture. Majority of respondents under this study were married (69.3\%) which could be attributed to the concentration of the majority of farmers within the marriageable age range of 26 to 45 years A large number of the respondents (48.7\%) have household size between 4 and 6 . The mean household size of the study sample was 4.96 . This may have positive implication on the on the strength of farm labour supply as their will be more family labour for farm work. The educational level of the respondents shows that about $42 \%$ have post primary education while $58 \%$ were below primary level. Farmers with higher levels of education are likely to be more efficient in the use of inputs than their counterpart with little or no education because education and literacy help to eradicate ignorance and promote adoption of innovation. 41 percent of the respondents have rice farming experience of between $6-10$ years. This is followed by 25.3 percent of the population with 11-15 years experience. 21.3 percent have farming experience between 0 to 5 years. On the whole about 12 percent of the respondents have over 15 years of rice farming experience. The mean farm size was 0.83 hectares, signifying that on the average, rice farmers in the study were small scale farm holders. $75 \%$ of the respondents have less than 1 hectare of farm land. This is the likely due to the problem of land fragmentation as a result of inheritance which is quite common in the Southwestern part of the country.

Table 1: Respondents' Distribution by Socioeconomic Characteristics

\begin{tabular}{|l|c|c|}
\hline Variables & Frequency & Percentage \\
\hline Age (yrs) & & \\
$<30$ & 25 & 16.7 \\
$31-40$ & 43 & 28.6 \\
$41-50$ & 59 & 39.4 \\
$51-60$ & 20 & 13.3 \\
$>60$ & 3 & 2.0 \\
Gender & 126 & 84.0 \\
Male & 24 & 16.0 \\
Female & & \\
Marital status & 34 & 22.7 \\
Single & 104 & 69.3 \\
Married & 12 & 8.0 \\
Divorced/widowed & & \\
Household size & 42 & 28.0 \\
$<3$ & & \\
\hline
\end{tabular}




\begin{tabular}{|l|c|c|}
\hline $4-6$ & 73 & 48.7 \\
$7-9$ & 24 & 16.0 \\
$>10$ & 11 & 7.3 \\
Educational status & 50 & \\
No formal education & 36 & 33.3 \\
Pry education & 52 & 24.0 \\
Secondary education & 12 & 34.6 \\
Tertiary education & & 08.1 \\
Farming experience (Years) & 32 & \\
$<5$ & 62 & 21.3 \\
$6-10$ & 38 & 41.4 \\
$11-15$ & 18 & 25.3 \\
$>15$ & 113 & 12.0 \\
Farm size (ha) & 29 & 75.3 \\
$<1$ ha & 8 & 19.4 \\
$1.1-2.0$ & & 5.3 \\
$>2$ & & \\
\hline
\end{tabular}

Source: Authors' computation from survey data

\subsection{Incidence of Malaria Attack}

The result in Table 2 shows that about 108 (72.0\%) of the 150 respondents indicated that they succumb to malaria attack at least once in a year. While the remaining 28.0 percent claim they do not experience the disease at all. 42.7 percent were incapacitated for between 1 and 10 days, 20\% experienced malaria between 11-20 days while 9\% have malaria over 20 days. However, the mean number of days of incapacitation was 10 days per year. $38 \%$ of the respondents indicated that they go to hospitals or health centers to receive treatments, 17.2 percent of them go to Chemists and patent stores, 15.6 percent of them practice self medication, 11.3 percent used herbs and10.2 percent of the respondents indicated that they rest when they have malaria. The implication of this finding is that most farmers are enlightened on the use of hospitals when they are sick. However, a significant percent of the farmers (15.6 percent) are still practicing self medication which should be discouraged since they diagnosis of the disease is very important before treatment can be administered. There were more responses than the number of respondents because there were multiple responses. Table 2 also shows that majority of the farmers use screens on their doors and windows to keep out mosquitoes and also keep their surroundings clean of bush. About $40 \%$ of the respondents indicated fever each time they have malaria, while 16.3 percent, 26.6 percent, 10.3 percent, 4.9 percent and 1.5 percent of the respondents indicated that they experience chill, headache, loss of appetite, dizziness and other symptoms respectively.

Table 2: Distribution of Respondents based on Malaria Attack

\begin{tabular}{|l|c|c|}
\hline Variable & Frequency & Percentage \\
\hline Susceptibility & 108 & \\
Yes & 42 & 72.0 \\
No & & 28.0 \\
Days of incapacitation & 64 & 42.7 \\
$<10$ & 30 & 20.0 \\
$11-20$ & 14 & 9.3 \\
$>20$ & & \\
Treatment source & 71 & 38.2 \\
Hospital / Health care & 32 & 17.2 \\
Chemists/patient medicine store & 14 & 7.5 \\
Traditional health practitioner & 29 & 15.6 \\
Self medication & 19 & 10.2 \\
Taking rest & 21 & 11.3 \\
Using of herbs & & \\
Preventive measures & 15 & 7.7 \\
Using mosquito nets & 41 & 21.1 \\
Draining stagnant water & \multicolumn{2}{|}{} \\
\hline
\end{tabular}




\begin{tabular}{|l|c|c|}
\hline Using screens on openings & 60 & 30.9 \\
Periodic use of insecticides & 18 & 9.3 \\
Good sanitation & 49 & 25.6 \\
Regular use of drugs & 9 & 4.6 \\
Others & 2 & 1.0 \\
Malaria Symptoms & 82 & \\
Fever & 33 & 40.4 \\
Chill & 54 & 16.3 \\
Headache & 21 & 26.6 \\
Loss of appetite & 10 & 10.3 \\
Dizziness & 3 & 4.9 \\
others & & 1.5 \\
\hline
\end{tabular}

Source: Authors' computation from survey data

\subsection{Determinants of Respondents' Incidence of Malaria Attack}

Tobit regression analysis (Table 3) was used to analyze the effects of some socioeconomic variables on the spread of malaria among rice farmers in the study area. The regression result shows that age and income of the respondent rice farmers were both significant at $1 \%$, household size and years of education of the respondents were significant at $5 \%$ while gender and number of hours worked per day were both significant at $10 \%$. Age as expected was significant because the older the farmer becomes, the more the likelihood of his susceptibility to malaria attack due to decreasing immunity against the disease.

Table 3: Tobit Regression Analysis

\begin{tabular}{|c|c|c|c|}
\hline Variable & Coefficient & Standard Error & Marginal Effect \\
\hline Constant & 0.6798837 & 0.1949807 & \\
\hline Age & $0.0102788^{* \star *}$ & 0.0038224 & $0.002787^{\star \star \star *}$ \\
\hline Gender & $-0.1733296^{*}$ & 0.0977534 & $-0.364923^{\star}$ \\
\hline Marital status & 0.0779776 & 0.0721279 & -0.063391 \\
\hline Household Size & $-0.0345524^{* *}$ & 0.0150208 & $-0.063993^{\star *}$ \\
\hline Years of Education & $-0.0138575^{* *}$ & 0.0062416 & $-0.026091^{* *}$ \\
\hline Farming Experience & 0.0036337 & 0.0078822 & -0.011815 \\
\hline Farm size & 0.041221 & 0.0794891 & -0.114567 \\
\hline Income & $-2.44 \mathrm{E}-06^{\star \star *}$ & 8.43E-07 & $-4.10 \mathrm{E}-06^{\star \star \star}$ \\
\hline Hours & $-0.032142^{\star}$ & 0.0166553 & -0.064786 \\
\hline Number of Observation & & 150 & \\
\hline$F(9,141)$ & & 8.62 & \\
\hline Prob $>F$ & & 0.0000 & \\
\hline Pseudo R² & & 74.75551 & \\
\hline Log Pseudo likelihood & & 0.2269 & \\
\hline
\end{tabular}

Source: Authors' computation from survey data

\subsection{Technical Efficiency of the Rice Farmers in the Study Area}

Estimation of the stochastic frontier model was by the Maximum Likelihood method using LIMDEP (Green, 1993). As shown in Table 4, the data were lumped together for the two states since the objective is to measure the efficiency between rice farmers with and without malaria. Farm size, seed and agro chemical were significant at 1\%, 5\%, and 10\% respectively. The predicted technical efficiency differs substantially among farmers as it ranges from 0.24 to 0.90 with mean technical efficiency of 0.75 . This implication of this is that the farmers were technically efficient but there is a potential of about 25 percent to improve the output of the farmers if health and production conditions are improved. As shown in Table 5 , Seed and farm size were significant at $5 \%$ and $1 \%$ respectively while other variables were not significant but positively correlated which shows that an increase in any of the variables would lead to an increase in the technical efficiency of the rice farmers. 
Table 4: Maximum Likelihood Estimates for the Stochastic Frontier Model

\begin{tabular}{lccc}
\hline Variable & Coefficient & Standard Error & T-ratio \\
\hline Constant & 10.2846 & 0.4108 & 25.035 \\
Farm size & 0.7095 & $7.41 \mathrm{E}-02$ & $9.570^{\star \star \star}$ \\
Fertilizer & 0.9394 & $4.28 \mathrm{E}-04$ & 0.21 \\
Agrochemical & 0.1004 & $5.24 \mathrm{E}-02$ & $1.918^{\star}$ \\
Seed & 0.1817 & $9.11 \mathrm{E}-02$ & $1.995^{\star \star}$ \\
Hours & 0.1362 & $1.27 \mathrm{E}-01$ & 1.071 \\
\hline
\end{tabular}

R-squared $=.781854$, Adjusted R-squared $=.77428$, LogAmemiyaPrCrt. $=-1.716$, Akaike Info. Crt. $=1.122$

${ }^{* *}$ significant at $1 \%$ level, ${ }^{* *}$ significant at $5 \%$ level, * significant at $10 \%$ level.

Source: Authors' computation from survey data.

Table 5: Determinants of Rice Farmers' Technical Efficiency

\begin{tabular}{lccc}
\hline Variable & Coefficient & Standard Error & T-ratio \\
\hline Constant & 10.5630 & 0.3950 & 26.743 \\
Farm size & $0.7173 \mathrm{e}-03$ & $0.9211 \mathrm{e}-01$ & $7.788^{\star \star \star}$ \\
Fertilizer & $0.1073 \mathrm{e}-01$ & $0.5378 \mathrm{e}-01$ & 0.002 \\
Agrochemical & $0.9877 \mathrm{e}-01$ & $0.8445 \mathrm{e}-01$ & 1.170 \\
Seed & 0.1877 & $0.6590 \mathrm{e}-01$ & $2.848^{\star \star}$ \\
Hours & 0.1322 & 0.1210 & 1.092 \\
Lamba & 1.0941 & 0.43010 & 2.541 \\
Sigma & 0.5013 & $0.4140 \mathrm{e}-01$ & 12.112 \\
Log likelihood & -76.5842 & & \\
Mean T.E. & 0.7525 & & \\
***ignificant at 1\% level, ${ }^{* *}$ significant at 5\% level, ${ }^{*}$ significant at 10\% level.
\end{tabular}

Source: Authors' computation from survey data.

\section{Conclusion and Recommendations}

Good health is an asset for agriculture, as healthy people can produce more and good nutrition contributes to it. Conversely, agriculture is an asset which contributes to good health, nutrition and resilience. When disease afflicts farmers or health of the farmers is hampered, agricultural productivity is reduced and this results into rising poverty. All of these responses can have adverse effects on the long-term labour productivity of farmers.

This study focused on investigating the socioeconomic effect of malaria on rice farmers' productivity. The study found that malaria is a key health concern for many households in southwest Nigeria. Malaria being a predominant cause of illness among rural farmers therefore causes a major drawback in labour supply and eventually agricultural production. The number of workday lost as a result of malaria illness poses a very serious threat to farmers' efficiency.

The effect of malaria attack on rice production is serious because Nigeria's agriculture is labour intensive and rainfed. The fact that Nigeria's agriculture is rain-fed requires farmers to timely prepare land, plant, weed and harvest to ensure that the crops' growth stages coincide with the most favourable health conditions. Therefore since malaria negatively affects the availability of labour, it adversely affects the possibility and timeliness of implementing these critical operations and ultimately negatively affects rice production. It was also found that the mean number of days of incapacitation for the farmers was 10 days.

The study further revealed the effect of socioeconomic variables on the incidence of malaria in the study area. The result of the Tobit regression showed that age, gender, marital status, income, hours spent and years of formal education were all significant at 1\%,10\%,5\%,1\%,10\% and 5\% respectively while household size, farming experience and farm size were not significant. Also, age, marital status, farming experience and farm size had positive relationships with malaria incidence. On the other hand, gender, household size, years of formal education, income and hours spent all had negative relationship with malaria incidence. The mean technical efficiency of the farmers was also found to be 75 percent, implying that the farmers were technically efficient but they still have 25 percent potential of improving their output.

It is therefore recommended that primary health care needs to be developed further and made accessible to the 
rural farmers. At the same time, the burden of disease can be lowered if the incidence of disease is reduced with carefully planned agricultural development programmes that do not produce negative externalities for the health sector and serious attention has to be paid to factors that affect farm labour productivity, including nutrition and health.

\section{References}

Adeola, C. (2002). Analysis of Economic Efficiency of Male and Female Rice Farmers in Ekiti State, Nigeria, NISER Monograph Series $15,2002$.

Akande, T. (2001). An Overview of the Nigerian Rice Economy, Research paper published by the Nigerian Institute of Social and Economic Research (NISER), Ibadan, 11pp.

Alaba, O.A. and Alaba, O. B. (2002). "Malaria in Children; Implications for the productivity of female caregivers in Nigeria". Proceeding of Annual Conference of the Nigerian Economic Society (NES), pp 395-413.

Aigner, D.J; A.K. Lovel and P Schmidt (1977) Formulation and Estimation of Sebchastic Production Function Models. Journal of Econometrics vol 6 pp 21-34.

Alves L. F., M.V. Andrade and P.B.R. Macedo (2003): Health and labor market in Brazil. Mimeograph.

Awoniyi S.O.M., Amos T.T. and Omole M.M (2010). "Rice farmers' productivity in Nigeria: How Malaria has not helped."

Battesse, G.E. and Coelli T.J. (1995) A Model for Technical Efficiency Effects in a Stochastic Frontier Production Function For Panel Data. Empirical Economics 20:325-332.

CHESTRAD (2000). Malaria, Poverty and Health, Center for Health Services Training. Research and Development International.

Coelli, T. J. 1994. "A guide to FRONTIER Version 4.1: A computer program for stochastic frontier production and cost function estimation". CEPA Working Paper 96/07. University of New England, Armidale, Australia.

Coluzzi, M. (1991). The clay feet of African giants and its African roots; hypotheses and inferences about origin, spread and control of " plasmodium falciparum". Parasitologia 41:277-283.

Eyo, E.O., Ele, I. E. Eyo, O.I. (2006): Occupational Health Problems, cited in Ogana M. U. (2010): Effect of Malaria attack on income and productivity loss among Artisanal Fisher-folk in Lake Ona.

Farrell, J. M. (1957). The Measurement of Productive Efficiency. J. Royal Stat. Soc., 120: 253-290.

Greene, W.H. 1980. "Maximum likelihood estimation of econometric frontier functions". Journal of Econometrics, 13(1): 27-56.

Kumbhakar, S.C., Gosh, T. McGuckin (1991)A Generalised Production Frontier Approach for Estimating Determinants of Inefficiency in US Dairy farms. Journal of Business and Economics Statistics, 9(3): 279-286.

Kwadwo Asenso-Okyere, Felix A. Asante, Jifar Tarekegn, and Kwaw S. Andam (2011). "Addressing the link between Agriculture, Malaria and Development in Nigeria" Conference paper for Levering Agriculture for improving nutrition and health. Pg 16.

Multilateral Initiative of Malaria (MIM), (2001): The Intolerable burden of Malaria. A new Look at Numbers. The American Journal of Tropical Medicine and Hygiene. Vol. 56(4) pp 282-287.

Mutero C. M., Blank H., Konradsen F. and van der Hoek W. (2005) Water management for controlling the breeding of Anopheles mosquitoes in rice irrigation schemes in Kenya. Acta Tropica 76.

National Malaria Control Programme (2005) Annual Report. Federal Ministry of Health, Nigeria.

Ogundele O.O. (2003) "Technology Differentials and Resource-Use Efficiency in Rice Production in Kaduna State." An Unpublished PhD thesis in the Department of Agricultural Economics, University of Ibadan, Nigeria.

Okoruwa, V. and Agulana, F. (2004) Sickness and Labour Among Farmers in Oyo and Osun States of Southwest Nigeria. Issues in African Rural Development Monograph series, ARPAN Winrock International.

Olayide SO, Heady EO (1982): Introduction to Agricultural Production Economics Ibadan: University of Ibadan Press, Nigeria.

Rougemont A, Breslow N, Brenner E Et Al. Et Al. (1991) Epidemiological basis for clinical diagnosis of childhood malaria in endemic zone in West Africa. Lancet 338, 1292-1295.

Sachs J and P. Malaney (2010) The Economic and Social Burden of Malaria. Insight Review Articles. Center for International Development, John F. Kennedy School of Government, Harvard University.

WARDA (1996). West Africa Rice Development Association Annual Report 1996, 59 pp.

W. H. O. (1999). World health report: Making a difference. Geneva: WHO.

W. H. O. (2002). "Malaria Early Warning Systems. Concepts, Indicators and Partners: a framework for field research in Africa." WHO/CDS/RBM/2001.32, Geneva.

W. H.O. (2008). World Malaria Report. Geneva. 